\title{
Journal of Teaching
}

in Physical Education

\section{Youth basketball coaches' perceptions and implementation of fundamental movement skills training: Towards a realist evaluation}

\begin{tabular}{|r|l|}
\hline Journal: & Journal of Teaching in Physical Education \\
\hline Manuscript ID & JTPE.2020-0306.R2 \\
\hline Manuscript Type: & Article \\
\hline Keywords: & survey, sports, motor learning, evaluation, mixed methods \\
\hline
\end{tabular}

\section{SCHOLARONE ${ }^{\text {Im }}$ Manuscripts}


Youth basketball coaches' perceptions and implementation of fundamental movement skills training: Towards a realist evaluation

Authors note:

This research received no funding and there are no conflicts of interest to report. 
Abstract

2 Purpose: To investigate youth basketball coaches' perceptions and implementation of fundamental 3 movement skills training (FMS). Method: Snowball and criterion-based sampling approaches were 4 used to survey youth basketball coaches $(n=79)$ beliefs and experiences relating to their perceptions 5 and implementation of non-basketball specific skills and FMS into practice. Realist Evaluation 6 inspired the analysis of descriptive statistics (means and frequencies) and reflexive qualitative 7 thematic analysis to inform the results. Results: It was found that the participants had a 8 comprehension of FMS and acknowledge their value in the long-term development of youth players. 9 However, there appeared to be varying levels of uptake amongst the surveyed coaches. 10 Discussion/Conclusion: The findings suggest there is a need for governing bodies to develop 11 innovative strategies to persuade youth basketball coaches to adopt non-sports specific movement skills to improve their practice.

\section{Keywords}

14 survey, sports, motor learning, evaluation, mixed methods 
Youth basketball coaches' perceptions and implementation of fundamental movement skills training: Towards a realist evaluation

Development models of youth sports are often criticized due to a lack of emphasis on generalized fundamental movement skills (FMS) (Bridge \& Toms, 2013; DiStefano et al., 2017; Liefeith et al., 2018). Furthermore, FMS are considered foundational for the development of sportsspecific skills, which experts have argued, that if left undeveloped may limit future performance (Arede et al., 2019; Barela, 2013; Jukic et al., 2019). FMS has conventionally been classified as locomotor, ball manipulation, and stability skills (Barnett et al., 2016). Hulteen et al. (2018) have extended conventional definitions to include more diverse movement skills such as leaping and hopping, cycling, treading water, and swimming, all of which can be honed through practice and instruction. From early childhood, rudimentary goal-oriented movements, form the basis for more advanced movement patterns (e.g., locomotive) to be developed (Hulteen et al., 2018). Thus, the development of rudimentary throwing and catching skills can later be refined for ball games and sport, such as American football, baseball, and basketball (Wormhoudt et al., 2018).

Research has tended to focus upon associations between FMS and physical activity levels, rather than transfer to sports-specific skills (cf. Barela, 2013; Cliff et al., 2009, 2012; Holfelder \& Schott, 2014). Systematic reviews by Holfelder and Schott (2014) and Logan et al. (2015) have highlighted the relationship between childhood FMS competence and physical activity during adolescence. Further, a substantial body of research (e.g., Leppänen et al., 2015; Pasulka et al., 2017; Read et al., 2016) has advocated for the use of FMS-based training to mitigate the risk of injury and burnout resulting from early sports specialization ${ }^{1}$. Bell et al. (2018) revealed through their metaanalysis that youth level athletes who were categorized as highly specialized (participating in a single sport) were at a significantly greater risk of injury compared to those categorized as moderate and low specialization (participating in multiple sports). To combat the risks associated with early specialization, initiatives have been developed to emphasize the development of FMS in children, encouraging coaches to incorporate them into programs of physical activity (Ford et al., 2011; Lloyd, Oliver, Faigenbaum, et al., 2015; Myer et al., 2011).

In 2016 the NBA released its youth basketball guidelines that were compiled by a multidisciplinary panel of experts (DiFiori et al., 2018). In addition to participation recommendations and the promotion of sports sampling, the guidelines recommended the incorporation of neuromuscular training (NMT) programs (Youth Basketball Guidelines), which typically include FMS based activities (Granacher et al., 2018; Hopper et al., 2017). Through a range of non-sports specific exercises, NMT programs typically target balance, the stretch-shortening cycle, and lower 
limb strength and power, which contribute to improved neuromuscular control (Faude et al., 2017; Granacher et al., 2018). Furthermore, although not exclusively, NMT programs commonly include athletic movement skills that underpin strength and conditioning exercises, such as squatting and hip flexion patterns, which have been associated with indicators of greater athletic performance (Lloyd, Oliver, Radnor, et al., 2015; Radnor et al., 2020; Woods et al., 2017). Moreover, NMT programs have been found to reduce risk factors for injury across youth athletic populations (Ayala et al., 2017; Bizzini \& Dvorak, 2015; DiStefano et al., 2010).

Despite the NBA's initiative being focused on injury prevention, and discourses relating to the promotion of youth athlete health and wellbeing, the adherence by youth coaches has been found to vary (Norcross et al., 2016; Owoeye et al., 2020; Räisänen et al., 2021). A recent study by Owoeye et al. (2020), found that coaches altered NMT programs based on perceived relevance to performance as well as player interest. Owoeye and colleagues' findings suggest a lack of comprehension for the importance of FMS in the development of youth basketball players. Given that it appears prudent for youth basketball coaches to incorporate non-basketball specific FMS content within their coaching practice, the current calls by the NBA (and other National Sporting Organizations) to incorporate FMS may be failing to resonate. Therefore, the purpose of the present study was to investigate youth basketball coaches' perceptions of FMS and the extent to which FMS are included within their coaching practice. We conclude this paper by discussing how a greater understanding of coaches' perceptions of FMS would improve the development of youth basketball players.

\section{Methods}

We used a mixture of snowball and criterion-based, sampling approaches to recruit potential participants (Smith et al., 2016; Sparkes, 2014). We utilized online survey methods because we were interested in surveying individuals from any nation who identified as basketball coaches (i.e., the criterion). The survey was advertised on social media platforms (e.g., Twitter and LinkedIn) and within online coaching communities (e.g., Basketball England's Hive platform, Basketball England's Talent Pathway WhatsApp group, and a WhatsApp group for sports coaching professionals located worldwide). The survey consisted of twelve questions devised by the first author (Table 1.). These questions included the country where the coaches were based, the sex and age group of players coached, and the number of practice sessions delivered. In addition, questions designed to assess the coaches' beliefs relating to non-basketball specific FMS were included, with open ended questions utilized to determine differences and commonalities between coaches' perceptions of FMS as they pertain to youth basketball development. Informed consent was included within the online survey and was obtained by all respondents. 
[Insert Table 1 near here]

A total of 92 youth basketball coaches responded to the surveys, with respondents providing responses to all survey items. However, 11 of the respondents were coaching basketball squads that were deemed not to be youth level (under 19 and above), and two respondents were found to have unintentionally submitted the survey twice. Therefore, each of these cases were removed and excluded from data analysis. From the remaining 79 coaches, a total of 58 were based in the United Kingdom (UK), representing the majority. Other countries included: Spain (8); the United States of America (USA) (5); Canada (2); and single respondents from Belgium, Finland, Indonesia, Jamaica, South Africa, and Qatar.

The age groups worked with by the coaches spanned age groups from under 10 years of age up to under 18. Within this, eleven of the respondents coached multiple age groups, a practice that appeared across the different countries where the coaches were based (Canada, Jamaica, Spain, Qatar, UK, USA). In terms of the gender of the players coached, 19 of the respondents coached exclusively females, 46 coached exclusively males, and 14 coached across both sexes.

\section{Analysis}

We analyzed our data using a mixed methods approach loosely inspired by realist evaluation methods developed by Pawson \& Tilley (1997) where we sought to focus on the mechanisms, context, and outcomes that mediated the implementation of FMS and non-specific movement skills by coaches in relation to their practice. Firstly, to assess outcomes (i.e., the uptake of FMS and non-movement skills) we conducted and reported the means and frequencies associated with the forced response questions to the survey. To explore how mechanisms (i.e., what drove people to implement FMS and non-movement skills) were mediated by context (i.e., the practicalities of coaching and the coaches environment) we analyzed open ended responses (questions five and nine) guided by reflexive thematic analysis techniques (V. Braun \& Clarke, 2006; Richards \& Hemphill, 2018; Spaaij et al., 2018; Trainor \& Bundon, 2020). Data was categorized into subthemes related to the commonalities that existed within the responses to each of the questions (Richards \& Hemphill, 2018; Spaaij et al., 2018; Trainor \& Bundon, 2020).

To code the data, we followed a similar precedent set forward by Spaaij et al., (2018). Two of the investigators independently read a proportion (10\%) of the transcripts and, using survey responses Microsoft Excel (Excel version 2103), coded passages of text firstly using an open (or initial meaning code) and secondly an axial (or categorization of open codes) coding scheme (Spaaij et al., 2016). For instance, the claim "Balance of priorities to cover including the mental, technical and tactical needs of the athletes. These are developed through $S \& C$ sessions" was initially coded as "context - 
balance of priorities". After similar statements related to the theme "balance of priorities" was open coded, some text would then be categorized a second time to further classify the statement. In this example, the statement would also be coded under the axial theme of "context - time management". The interpretation of the identified passages and codes were debated at length by the three authors. The first author then coded the rest of the responses line by line, and a third investigator reviewed the coding.

\section{Considerations of Reliability and Validity}

Consistent with our mixed methods approach inspired by Pawson and Tilley's (1997) method and theory of realist evaluation, validity and quality were guided by ontological assumptions of critical realism (Jagosh, 2020; Pawson \& Tilley, 1994) that balanced considerations related to truth being both knowable but also subject to interpretation and context. Specifically, we used the following criteria to reflexively guide our decisions: We assessed the topic's worthiness (What are coaches' perceptions of FMS? And how are these perceptions being used to inform practice and pedagogical knowledge) and the importance and significance of the work to the broader scholarly field (will this research address a gap in the literature and build upon applied and theoretical understandings of FMS and sport pedagogy?) (B. Smith et al., 2015; Tracy, 2010). We challenged ourselves to produce a rigorous account of the data (is the data nuanced, and does it provide meaningful insights?). We strove for constancy and transparency in how we arrived at our conclusions (is the research clearly described and did the purpose, methods, and findings align?). Drawing on a previous approach described by Smith and colleagues (2016), we contend that the answer to these questions is yes; however, to engage in a reflexive practice, following this precedent, the second and third authors acted as 'critical friends,' providing a theoretical sounding board to explore alternative interpretations as we classified the data into themes (B. Smith et al., 2016). Through these processes we have endeavored to provide the opportunity for others to judge our research quality and value.

\section{Descriptive Statistics}

When participants were asked questions related to outcomes "do you include non-basketball specific exercises / activities in the warm-up ahead of main practice content?", 58 of the 79 coaches responded "yes", while 17 responded "sometimes" and four coaches "no". In response to the question, "would you feel confident to deliver non-basketball specific warm up exercises that target general athleticism?" 75 coaches responded “yes", and four coaches responded "no". There were 76 coaches who responded "yes" to the question, "do you believe there would be value in including general athletic exercises into your coaching session?" and three coaches responded with 
145 the answer "maybe". In terms of the number of exposures to non-specific exercises (squat; lunge; hip hinge; landing technique; pushing; bridging (or 'plank' variations), 20 coaches' response was once per week, 30 coaches' response was twice per week, 17 coaches responded with three times per week, and 12 coaches responded with four or more times per week. In response to question 10, where coaches were to indicate which athletic movement patterns they included from the choices provided, the number of responses for the inclusion of the squat were 70 (89\%); 74 (94\%) for the lunge; 56 (71\%) for landing technique; 43 (54\%) for pushing patterns; 41 (52\%) for the hip-hinge; 39 (49\%) for bridging or plank activities; and 34 (43\%) for pulling patterns.

When asked "how proficient would you rate the players to be at performing these athletic movement patterns with respect to control and stability", 14 coaches' response was "very"; 57 coaches responded with "fairly"; and 8 responded with "not". Relating to basketball coaching frequency with respective squads, there were 20 ambiguous responses which were removed from the analysis for this question. In addition, due to working with players as part of a national squad, two of the reported only delivering supervised coaching sessions with their respective squads once per month and were also removed from the analysis for this question. The median number of sessions delivered per week was reported as two, while the minimum number was one and the maximum was nine. For session duration, from 55 respondents, the median was 90-minutes, with a maximum reported duration of 170-minutes and a minimum of 45-minutes.

\section{Qualitative findings}

Analysis of the open-ended qualitative responses indicate that contextual concerns related to professional knowledge and coaching cultures (see for example: Hammond et al., 2020) impacted their ability to improve FMS,

$$
\begin{aligned}
& \text { "I coach basketball not } S \& C, S \& C \text { should be given its own specific sessions” (Coach } \\
& \text { Gallagher). }
\end{aligned}
$$

"There are lots of non basketball specific skills that would add value to individual players to enhance and improve performance and athleticism" (Coach Arthurs).

"I answered yes to all questions, but I would also state that I don't have a concrete understanding of said movements. I believe in the concept. I more so follow experts I trust like Alan Stein and Brian McCormick to guide me” (Coach White). 
In the present study, the statement from Coach Gallagher suggests that they regard such content as equivalent to strength and conditioning training $(\mathrm{S} \& \mathrm{C})$, which not only presents a narrow view FMS and its value, but also suggests a denial of responsibility for wider development of youth players. Furthermore, the results for the proportions of athletic skills exercises included within the coaches' practices are suggestive of a disregard for the development of broad FMS.

The lunge and squat patterns were the most widely reported exercises and were deemed to have greater basketball relevance. Nevertheless, other responses contributed to the emergence of the subtheme independent entity, and included the following two responses:

"Balance of priorities to cover including the mental, technical and tactical needs of the athletes. These are developed through S\&C sessions" (Coach McCarroll).

"I do not lead warmups, my role as a coach is more of technical/analytical in nature" (Coach Bell).

The meaning established from the responses of coaches McCarroll and Bell is one which highlights a potential lack of appreciation for the intertwining nature of movement and coordinative dynamics (W. Smith, 2016). While Coach McCarroll and Coach Bell's perspectives are not deliberately harmful, arguably they are deflecting their responsibility for enriching the athletic development of their players and safeguarding their health and welfare (i.e., from an injury prevention perspective). In contrast, the subtheme non-specific and basketball specific movement skill interdependency highlighted how some coaches considered FMS to not be disparate from basketball specific fundamental movement skills (W. Smith, 2016). This meant that some of our participants dismissed the need to emphasize FMS and apply the same pedagogical approach across all movement skills. This is somewhat reinforced by one coach who stated that: "....to elaborate most of these activities will be done with some sort of basketball incorporated" (Coach Ashcroft). While such interactivity of FMS and sports skills is suggestive of an appreciation of the complimentary nature of all motor skills, coaches may also be ignoring the need incorporate FMS in isolation as well as in context (Barnett et al., 2016). Overall, coaches who aligned with the subtheme non-specific and basketball specific movement skill interdependency are likely to include FMS only haphazardly as part of sportsspecific drills and exercises and thus defeating the purpose of incorporating FMS in the first place.

When reasons for not including non-basketball specific FMS in practices and the coaches' descriptions of FMS themes were compared, we found a lack of consensus and which, in turn, may 
YOUTH BASKETBALL COACHES AND FMS

211

unintentionally lead to an undervaluing of their importance. For example, the child focused subtheme intimates that FMS are exclusively children's activities, as one coach described:

“Basic movements that children carry out. Throwing, catching, running etc.” (Coach Kelly)

Similarly, another coach responded with:

"The motor skills of a children [sic] and mechanics" (Coach Jones)

These descriptions from Coach Kelly and Coach Jones, while not incorrect, could be interpreted as somewhat limiting. Such limiting notions are reenforced by Coaches' Weller and Meighan:

"Shooting, handling, passing, defense and rebound" (Coach Weller).

"The base of the basketball game, there are several technical fundamentals aspects to be teach [sic]” (Coach Meighan).

The responses from Coaches' Weller and Meighan highlight a limited appreciation of FMS and its necessary role in implementing a holistic approach to youth athlete development (Mostafavifar et al., 2013). Importantly, these views were not representative of all coaches in survey. The subthemes, skills for general function, foundation movements, and athletic performance related, were more indicative of the notion that non-specific FMS can provide important foundations for sports-specific skills to be built upon:

"FMS are the basic or primary movements that all other sport movements or movements can be built upon" (Coach Starkey).

"A performers [sic] ability to carry out functional and fundamental movements in a variety of contexts and the [sic] in a basketball context apply to enable skills development" (Coach Archer).

In sum, our qualitative findings consistent with realist evaluation perspectives suggests coaches implementation of FMS mechanisms within their practices are constrained by contextual factors 
related to professional cultures and knowledge (Hammond et al., 2020; O'Gorman et al., 2021). While coaches may appreciate the value of FMS in developing favorable outcomes (e.g., basketball-specific skills) there is a need to think about how coaches can be better supported in context to implement and achieve outcomes and benefits (e.g., injury mitigation, and improved movement vocabulary) associated with the implementation of FMS. In addition to the athletic performance related subtheme, it appears that these coaches are cognizant, to some degree, of the importance of FMS in the development of basketball players. However, the lack of consistency in the coaches' responses within this overarching theme, further highlights the need to improve coaching knowledge.

\section{Discussion}

Our findings that context mediates enactment of behavior mechanisms seems to be consistent with recent studies (Räisänen et al. 2021; Owoeye et al., 2020) and the findings related to realist evaluation (Mitchell, 1997; Pawson \& Tilley, 1994), and policy enactment studies in physical education and sport pedagogy (Hammond et al., 2020; Landi et al., 2021; O'Gorman et al., 2021). Owoeye et al. (2020) found coaches were inclined to remove strength and balance related tasks in favor of exercises deemed to be more relevant to basketball performance. Similar findings were reflected in the study by Räisänen et al. (2021) into the use of NMT-based warm-ups by youth basketball coaches, which found $48 \%$ of coaches spent 10 -minutes of less on the warm-up component in their practices. Therefore, it is important not to understate the impact of socialization (Richards et al., 2013; Richards \& Templin, 2012; Wright et al., 2021) and contextual professional cultures (e.g., Hammond et al., 2020; O'Gorman et al., 2021) in prompting coaches to hold sports-specificity in higher regard than broader aspects of player development as they attempt to implement initiatives such as FMS and non-sport skills into their practice.

However, problems associated with coaches' perceptions have been previously highlighted in the study by Jukic et al. (2019) into youth soccer players. In their study, Jukic and colleagues found that FMS to be more important in distinguishing player levels compared to the coaches' subjective evaluations of player performances, highlighting the existence of disparities between coaches' perceptions and objective markers of performance capabilities. Indeed, coaches decision making regarding talent identification has recently been found to be based mainly upon tacit knowledge and instinct in place of valid criterion (Roberts et al., 2019). Moreover, it demonstrates that, again contextual dimensions related to coaching knowledge and dispositions are tilted towards sportsspecific skill development potentially at the cost of long-term development and player welfare. The literature (DiStefano et al., 2017; Pasulka et al., 2017; Zoellner et al., 2021) has found for instance, that single sport specialization is an outcome associated with limited motor skill development, risk of 
277 278 279 280 281 282 283 284 285 286 287 288 289 290 291 292 293 294 295 296 297 298 299 300 301 302 303 304 305 306 307 308 309

injury, and burnout syndrome (Mostafavifar et al., 2013). In youth basketball players, Leppänen et al (2015) found a high prevalence of overuse injury to the knee among both males and females. Therefore, any notion of non-sports specific movement skill training as a separate training form may be deemed as problematic for the long-term health and development of youth basketball players (DiCesare et al., 2019; DiFiori et al., 2017; DiStefano et al., 2017).

Collectively our findings appear to highlight a disregard for a holistic approach to the development of youth players in favor of talent identification (Liefeith et al., 2018; Rongen et al., 2018; Soares et al., 2020), suggesting that the education of youth basketball coaches may be a contributing factor. Indeed, education regarding basketball-specific injury prevention was suggested to be an area to address in the study by Räisänen et al. (2021), in response to their findings that coaches $67 \%$ of the coaches surveyed expected players to experience injury during the next season. Moreover, in a study by Saunders et al. (2010), youth netball coaches identified educational resources as an importance factor in NMT program implementation. Despite identifying restricted time and program length as barriers, the majority of the coaches believed it was effective in improving athleticism and reducing injury risk (Saunders et al., 2010). Similarities can therefore be drawn between coaches in both the Räisänen et al. (2021) and Saunders et al. (2010) studies and the coaches in the present study, highlighting the potential requirement for improved coach education. However, as a discipline, sports science, has been previously implicated in the creation of barriers through the overuse of jargon, and for the lack of dissemination of relevant information to coaches (Martindale $\&$ Nash, 2013). In this regard, it may be that a more clearly defined rationale for the inclusion of FMS is necessary for youth basketball coaches to place a greater emphasis on their development within practices in order to make such coach education interventions as contextually relevant as possible (cf. Cassidy et al., 2006; Cope et al., 2021; Cushion et al., 2003; Tinning, 2011).

We recommend that national sports organizations and other bodies responsible for coach education improve their rationale for the inclusion of FMS, ensuring its purpose is clear, and elaborated upon more greatly regarding its place in the long-term development of youth basketball players. In place of a dichotomized perspective of FMS and basketball, coaches need to shift to emphasize complimentary pairing that better accounts for the complexity of skilled action (Santos et al., 2017; Santos et al., 2016; Smith, 2016) as well as related reduction in risk factors for injury in youth athletes (DiFiori et al., 2017; Owoeye et al., 2020). Developers might want to explore the adoption of degeneracy and the functional role of movement variability (Seifert et al., 2014) within coach education programs. Degeneracy represents the ability of an individual to vary how a skill is executed by adapting their coordinative patterns to meet the goal of the task (Seifert et al., 2014). 
Moreover, expert performers are understood to rely less on a fixed movement strategy, and instead are able to apply different coordinative movement solutions to meet the requirements of a task (Mason, 2015). Therefore, given that functional variability is understood to occur in skilled movement (Komar et al., 2015), and the highly variable conditions that characterize game-based sports such as basketball, degeneracy of the nervous system is an feature important skilled performance (Mason, 2015).

From a motor skill development perspective, the Athletic Skills Model (Wormhoudt et al., 2018), advocates for the development of FMS to enhance the acquisition of sports specific skills, although we suggest that future studies might want to explore the concept of degeneracy as a way of better represent the interdependency of FMS and sports skills. Intertwining ideas from degeneracy encourages a move away from the dichotomizing of FMS and sports-specific skill development, and instead encourages the need to emphasize their development with a level of isolated focus so that the skills receive adequate attention to appropriately develop. Moreover, the notion of a limited FMS as a proficiency barrier to the acquisition of basketball specific skills may steer coaches to incorporate more focused attention to the pedagogical approaches applied.

A limitation of this study is that we are asking coaches to describe their practice in relation to the implementation of FMS and non-sport skills. Thus, we want to emphasize that we are only exploring the experiences of coaching from perspectives of the coaches themselves and that we cannot therefore assume that the participants have any depth of awareness of their own practice (Leeder et al., 2019; Partington \& Cushion, 2013). We argue future research is required to explore the implementation of FMS interventions in specific jurisdictions to better understand multiple dimensions of resistance when it comes to the implementation of policy in coaching practice. While the configuration of sport delivery (organization, policy, and funding) is unique to each country, what was striking from our study was that coaches were facing similar dilemmas in different locations in a diverse international sample, and we believe this study could provide a springboard for a more focused realist evaluation of the implementation of FMS skills in the future.

While our study is not statistically generalizable, we argue that other scholars and policymakers may be able to glean insights and following (B. Smith, 2018), we argue that when our work is read in conjunction with others, generalizability might be grasped on the basis of recognition of similarities and differences to which other social science pedagogues familiar with the motor learning work cited (e.g., O’Sullivan et al., 2020; Renshaw \& Chow, 2019; Young et al., 2020). We also argue there are transferable insights and generalizability where others can infer or translate our findings to other contexts: such as Physical Education (cf. (Haegele, 2019; Richards et al., 2013; 
343 Richards \& Templin, 2012; Wright et al., 2021) or in other areas of coaching policy interventions (cf. 344 Hammond et al., 2020; O’Gorman et al., 2021)

345 In sum, the importance of FMS has been well documented within youth development related 346 literature (Barnett et al., 2016; Hulteen et al., 2018; Lloyd, Oliver, Faigenbaum, et al., 2015). The 347 results of the present study show that youth basketball coaches have a diverse comprehension of what 348 FMS represent and, despite highlighting an appreciation of their importance as well as indicating 349 confidence in including athletic movement skills within their warm-up protocols, there appears to be 350 barriers to their inclusion. However, while discourse around the health and well-being of the 351 developing players should provide sufficient rationale to consistently incorporate FMS within 352 practices, it appears that a more relatable, basketball-specific, layer should be added. The concept of 353 degeneracy may provide the important link between FMS development and basketball-specific 354 performance.

1. Early sports-specialization, which represents participation in a single sport, has been associated with increased risk of injuries in youth level athletes ( $\leq 18$ years of age) (Bell et al., 2018). In this regard, increased injury risk is understood to relate to the intensity of year-round sports-specific practice and competition (Sugimoto et al., 2019), and the repetitive overuse of anatomical structures (Kraan et al., 2019; Leppänen et al., 2017)

\section{Acknowledgements}

We would like to express our sincere gratitude to the two anonymous reviewers, Dr. K. Andrew R. Richards and Dr. Heather Erwin for their thoughtful comments. There thoughts have enhanced the manuscript and we are deeply grateful for their insight and labor. 
YOUTH BASKETBALL COACHES AND FMS

\section{References}

Arede, J., Esteves, P., Ferreira, A. P., Sampaio, J., \& Leite, N. (2019). Jump higher, run faster: Effects of diversified sport participation on talent identification and selection in youth basketball. Journal of Sports Sciences, 37(19), 2220-2227. https://doi.org/10.1080/02640414.2019.1626114

Ayala, F., Pomares-Noguera, C., Robles-Palazón, F., del Pilar García-Vaquero, M., Ruiz-Pérez, I., Hernández-Sánchez, S., \& De Ste Croix, M. (2017). Training Effects of the FIFA 11+ and Harmoknee on Several Neuromuscular Parameters of Physical Performance Measures. International Journal of Sports Medicine, 38(04), 278-289. https://doi.org/10.1055/s-0042121260

Barela, J. A. (2013). Fundamental motor skill proficiency is necessary for children's motor activity inclusion. Motriz: Revista de Educação Física, 19(3), 548-551. https://doi.org/10.1590/S1980-65742013000300003

Barnett, L. M., Stodden, D., Cohen, K. E., Smith, J. J., Lubans, D. R., Lenoir, M., Iivonen, S., Miller, A. D., Laukkanen, A., Dudley, D., Lander, N. J., Brown, H., \& Morgan, P. J. (2016). Fundamental Movement Skills: An Important Focus. Journal of Teaching in Physical Education, 35(3), 219-225. https://doi.org/10.1123/jtpe.2014-0209

Barris, S., Farrow, D., \& Davids, K. (2014). Increasing Functional Variability in the Preparatory Phase of the Takeoff Improves Elite Springboard Diving Performance. Research Quarterly for Exercise \& Sport, 85(1), 97-106.

Bell, D. R., Post, E. G., Biese, K., Bay, C., \& Valovich McLeod, T. (2018). Sport Specialization and Risk of Overuse Injuries: A Systematic Review With Meta-analysis. Pediatrics, 142(3), e20180657. https://doi.org/10.1542/peds.2018-0657

Bizzini, M., \& Dvorak, J. (2015). FIFA 11+: An effective programme to prevent football injuries in various player groups worldwide - a narrative review. British Journal of Sports Medicine, 49(9), 577-579. https://doi.org/10.1136/bjsports-2015-094765

Braun, A., Ball, S. J., Maguire, M., \& Hoskins, K. (2011). Taking context seriously: Towards explaining policy enactments in the secondary school. Discourse: Studies in the Cultural Politics of Education, 32(4), 585-596. https://doi.org/10.1080/01596306.2011.601555

Braun, V., \& Clarke, V. (2006). Using thematic analysis in psychology. Qualitative Research in Psychology, 3(2), 77-101. https://doi.org/10.1191/1478088706qp063oa

Bridge, M. W., \& Toms, M. R. (2013). The specialising or sampling debate: A retrospective analysis of adolescent sports participation in the UK. Journal of Sports Sciences, 31(1), 8796. https://doi.org/10.1080/02640414.2012.721560

Button, C., Macleod, M., Sanders, R., \& Coleman, S. (2003). Examining Movement Variability in the Basketball Free-Throw Action at Different Skill Levels. Research Quarterly for Exercise and Sport, 74(3), 257-269. https://doi.org/10.1080/02701367.2003.10609090

Cassidy, T., Potrac, P., \& McKenzie, A. (2006). Evaluating and Reflecting upon a Coach Education Initiative: The CoDe of Rugby. The Sport Psychologist, 20(2), 145-161. https://doi.org/10.1123/tsp.20.2.145

Cliff, D. P., Okely, A. D., Morgan, P. J., Jones, R. A., Steele, J. R., \& Baur, L. A. (2012).

Proficiency Deficiency: Mastery of Fundamental Movement Skills and Skill Components in Overweight and Obese Children. Obesity, 20(5), 1024-1033. https://doi.org/10.1038/oby.2011.241 
Cliff, D. P., Okely, A. D., Smith, L. M., \& McKeen, K. (2009). Relationships between Fundamental Movement Skills and Objectively Measured Physical Activity in Preschool Children. Pediatric Exercise Science, 21(4), 436-449. https://doi.org/10.1123/pes.21.4.436

Cope, E., Cushion, C. J., Harvey, S., \& Partington, M. (2021). Investigating the impact of a Freirean informed coach education programme. Physical Education and Sport Pedagogy, 26(1), 6578. https://doi.org/10.1080/17408989.2020.1800619

Cushion, C. J., Armour, K. M., \& Jones, R. L. (2003). Coach Education and Continuing Professional Development: Experience and Learning to Coach. Quest, 55(3), 215-230. https://doi.org/10.1080/00336297.2003.10491800

DiCesare, C. A., Montalvo, A., Foss, K. D. B., Thomas, S. M., Hewett, T. E., Jayanthi, N. A., \& Myer, G. D. (2019). Sport Specialization and Coordination Differences in Multisport Adolescent Female Basketball, Soccer, and Volleyball Athletes. Journal of Athletic Training, 54(10), 1105-1114. https://doi.org/10.4085/1062-6050-407-18

DiFiori, J. P., Brenner, J. S., Comstock, D., Côté, J., Güllich, A., Hainline, B., \& Malina, R. (2017). Debunking early single sport specialisation and reshaping the youth sport experience: An NBA perspective. British Journal of Sports Medicine, 51(3), 142-143. https://doi.org/10.1136/bjsports-2016-097170

DiFiori, J. P., Güllich, A., Brenner, J. S., Côté, J., Hainline, B., Ryan, E., \& Malina, R. M. (2018). The NBA and Youth Basketball: Recommendations for Promoting a Healthy and Positive Experience. Sports Medicine, 48(9), 2053-2065. https://doi.org/10.1007/s40279-018-0950-0

DiStefano, L. J., Beltz, E. M., Root, H. J., Martinez, J. C., Houghton, A., Taranto, N., Pearce, K., McConnell, E., Muscat, C., Boyle, S., \& Trojian, T. H. (2017). Sport Sampling Is Associated With Improved Landing Technique in Youth Athletes. Sports Health, 10(2), 160-168. https://doi.org/10.1177/1941738117736056

DiStefano, L. J., Padua, D. A., Blackburn, J. T., Garrett, W. E., Guskiewicz, K. M., \& Marshall, S. W. (2010). Integrated Injury Prevention Program Improves Balance and Vertical Jump Height in Children: Journal of Strength and Conditioning Research, 24(2), 332-342. https://doi.org/10.1519/JSC.0b013e3181cc2225

Edelman, G. M., \& Gally, J. A. (2001). Degeneracy and complexity in biological systems. Proceedings of the National Academy of Sciences, 98(24), 13763-13768. https://doi.org/10.1073/pnas.231499798

Emery, C. A., \& Pasanen, K. (2019). Current trends in sport injury prevention. Best Practice \& Research Clinical Rheumatology, 33(1), 3-15. https://doi.org/10.1016/j.berh.2019.02.009

Faude, O., Rössler, R., Petushek, E. J., Roth, R., Zahner, L., \& Donath, L. (2017). Neuromuscular Adaptations to Multimodal Injury Prevention Programs in Youth Sports: A Systematic Review with Meta-Analysis of Randomized Controlled Trials. Frontiers in Physiology, 8, 791. https://doi.org/10.3389/fphys.2017.00791

Ford, P., De Ste Croix, M., Lloyd, R., Meyers, R., Moosavi, M., Oliver, J., Till, K., \& Williams, C. (2011). The Long-Term Athlete Development model: Physiological evidence and application. Journal of Sports Sciences, 29(4), 389-402. https://doi.org/10.1080/02640414.2010.536849

Granacher, U., Puta, C., Gabriel, H. H. W., Behm, D. G., \& Arampatzis, A. (2018). Editorial: Neuromuscular Training and Adaptations in Youth Athletes. Frontiers in Physiology, 9, 1264. https://doi.org/10.3389/fphys.2018.01264

Haegele, J. A. (2019). Inclusion Illusion: Questioning the Inclusiveness of Integrated Physical Education: 2019 National Association for Kinesiology in Higher Education Hally Beth Poindexter Young Scholar Address. Quest, 71(4), 387-397. https://doi.org/10.1080/00336297.2019.1602547 
Hammond, A. M., Penney, D., \& Jeanes, R. (2020). Sport coaches as policy actors: An investigation of the interpretation and enactment of disability and inclusion policy in swimming in Victoria Australia. Sport, Education and Society, 25(5), 570-585. https://doi.org/10.1080/13573322.2019.1628013

Holfelder, B., \& Schott, N. (2014). Relationship of fundamental movement skills and physical activity in children and adolescents: A systematic review. Psychology of Sport and Exercise, 15(4), 382-391. https://doi.org/10.1016/j.psychsport.2014.03.005

Hopper, A. J., Haff, E. E., Joyce, C., Lloyd, R. S., \& Haff, G. G. (2017). Neuromuscular Training Improves Lower Extremity Biomechanics Associated with Knee Injury during Landing in 11-13 Year Old Female Netball Athletes: A Randomized Control Study. Frontiers in Physiology, 8, 883. https://doi.org/10.3389/fphys.2017.00883

Hulteen, R. M., Morgan, P. J., Barnett, L. M., Stodden, D. F., \& Lubans, D. R. (2018). Development of Foundational Movement Skills: A Conceptual Model for Physical Activity Across the Lifespan. Sports Medicine, 48(7), 1533-1540. https://doi.org/10.1007/s40279018-0892-6

Jagosh, J. (2020). Retroductive theorizing in Pawson and Tilley's applied scientific realism. Journal of Critical Realism, 19(2), 121-130. https://doi.org/10.1080/14767430.2020.1723301

Jukic, I., Prnjak, K., Zoellner, A., Tufano, J. J., Sekulic, D., \& Salaj, S. (2019). The Importance of Fundamental Motor Skills in Identifying Differences in Performance Levels of U10 Soccer Players. Sports, 7(7). https://doi.org/10.3390/sports 7070178

Komar, J., Chow, J.-Y., Chollet, D., \& Seifert, L. (2015). Neurobiological degeneracy: Supporting stability, flexibility and pluripotentiality in complex motor skill. Acta Psychologica, 154, 26-35. https://doi.org/10.1016/j.actpsy.2014.11.002

Kraan, R. B. J., Nobel, D. de, Eygendaal, D., Daams, J. G., Kuijer, P. P. F. M., \& Maas, M. (2019). Incidence, prevalence, and risk factors for elbow and shoulder overuse injuries in youth athletes: A systematic review. Translational Sports Medicine, 2(4), 186-195. https://doi.org/10.1002/tsm2.82

Landi, D., Walton-Fisette, J. L., \& Sutherland, S. (2021). Physical Education Policy Research in the United States: Setting a New Orientation. Quest, 73(1), 45-62. https://doi.org/10.1080/00336297.2020.1866042

Leeder, T. M., Russell, K., \& Beaumont, L. C. (2019). "Learning the Hard Way": Understanding the Workplace Learning of Sports Coach Mentors. International Sport Coaching Journal, 6(3), 263-273. https://doi.org/10.1123/iscj.2018-0069

Leppänen, M., Pasanen, K., Kannus, P., Vasankari, T., Kujala, U., Heinonen, A., \& Parkkari, J. (2017). Epidemiology of Overuse Injuries in Youth Team Sports: A 3-year Prospective Study. International Journal of Sports Medicine, 38(11), 847-856. https://doi.org/10.1055/s0043-114864

Leppänen, M., Pasanen, K., Kujala, U. M., \& Parkkari, J. (2015). Overuse injuries in youth basketball and floorball. Open Access Journal of Sports Medicine, 173. https://doi.org/10.2147/OAJSM.S82305

Liefeith, A., Kiely, J., Collins, D., \& Richards, J. (2018). Back to the Future - in support of a renewed emphasis on generic agility training within sports-specific developmental pathways. Journal of Sports Sciences, 36(19), 2250-2255. https://doi.org/10.1080/02640414.2018.1449088

Lloyd, R. S., Oliver, J. L., Faigenbaum, A. D., \& Howard, R. (2015). Long-term athletic development- part 1: A pathway for all youth. Journal of Strength and Conditioning Research, 29(5), 12. https://doi.org/10.1519/JSC.0000000000000756

Lloyd, R. S., Oliver, J. L., Radnor, J. M., Rhodes, B. C., Faigenbaum, A. D., \& Myer, G. D. (2015). Relationships between functional movement screen scores, maturation and physical 
performance in young soccer players. Journal of Sports Sciences, 33(1), 11-19. https://doi.org/10.1080/02640414.2014.918642

Logan, S. W., Kipling Webster, E., Getchell, N., Pfeiffer, K. A., \& Robinson, L. E. (2015). Relationship Between Fundamental Motor Skill Competence and Physical Activity During Childhood and Adolescence: A Systematic Review. Kinesiology Review, 4(4), 416-426. https://doi.org/10.1123/kr.2013-0012

Martindale, R., \& Nash, C. (2013). Sport science relevance and application: Perceptions of UK coaches. Journal of Sports Sciences, 31(8), 807-819. https://doi.org/10.1080/02640414.2012.754924

Mason, P. H. (2015). Degeneracy: Demystifying and destigmatizing a core concept in systems biology. Complexity, 20(3), 12-21. https://doi.org/10.1002/cplx.21534

Mitchell, K. (1997). Encouraging young women to exercise: Can teenage magazines play a role? Health Education Journal, 56(3), 264-273. https://doi.org/10.1177/001789699705600306

Morley, D., Till, K., Ogilvie, P., \& Turner, G. (2015). Influences of gender and socioeconomic status on the motor proficiency of children in the UK. Human Movement Science, 44, 150156. https://doi.org/10.1016/j.humov.2015.08.022

Mostafavifar, A. M., Best, T. M., \& Myer, G. D. (2013). Early sport specialisation, does it lead to long-term problems? British Journal of Sports Medicine, 47(17), 1060-1061. https://doi.org/10.1136/bjsports-2012-092005

Myer, G. D., Faigenbaum, A. D., Ford, K. R., Best, T. M., Bergeron, M. F., \& Hewett, T. E. (2011). When to initiate integrative neuromuscular training to reduce sports-related injuries in youth? Current Sports Medicine Reports, 10(3), 155-166. https://doi.org/10.1249/JSR.0b013e31821b1442

Newell, K. M. (2020). What are Fundamental Motor Skills and What is Fundamental About Them? Journal of Motor Learning and Development, 8(2), 280-314. https://doi.org/10.1123/jmld.2020-0013

$\mathrm{Ng}$, J. L., \& Button, C. (2018). Reconsidering the fundamental movement skills construct: Implications for assessment. Movement \& Sport Sciences - Science \& Motricité, 102, 19-29. https://doi.org/10.1051/sm/2018025

Norcross, M. F., Johnson, S. T., Bovbjerg, V. E., Koester, M. C., \& Hoffman, M. A. (2016). Factors influencing high school coaches' adoption of injury prevention programs. Journal of Science and Medicine in Sport, 19(4), 299-304. https://doi.org/10.1016/j.jsams.2015.03.009

O’Gorman, J., Partington, M., Potrac, P., \& Nelson, L. (2021). Translation, intensification and fabrication: Professional football academy coaches' enactment of the Elite Player Performance Plan. Sport, Education and Society, 26(3), 309-325. https://doi.org/10.1080/13573322.2020.1726313

O’Sullivan, M., Davids, K., Woods, C. T., Rothwell, M., \& Rudd, J. (2020). Conceptualizing Physical Literacy within an Ecological Dynamics Framework. Quest, 72(4), 448-462. https://doi.org/10.1080/00336297.2020.1799828

Owoeye, O. B. A., Emery, C. A., Befus, K., Palacios-Derflingher, L., \& Pasanen, K. (2020). How much, how often, how well? Adherence to a neuromuscular training warm-up injury prevention program in youth basketball. Journal of Sports Sciences, 1-9. https://doi.org/10.1080/02640414.2020.1782578

Partington, M., \& Cushion, C. (2013). An investigation of the practice activities and coaching behaviors of professional top-level youth soccer coaches: Practice activities and behaviors of youth soccer coaches. Scandinavian Journal of Medicine \& Science in Sports, 23(3), 374-382. https://doi.org/10.1111/j.1600-0838.2011.01383.x 
Pasulka, J., Jayanthi, N., McCann, A., Dugas, L. R., \& LaBella, C. (2017). Specialization patterns across various youth sports and relationship to injury risk. The Physician and Sportsmedicine, 45(3), 344-352. https://doi.org/10.1080/00913847.2017.1313077

Pawson, R., \& Tilley, N. (1994). WHAT WORKS IN EVALUATION RESEARCH? The British Journal of Criminology, 34(3), 291-306. JSTOR.

Pawson, R., \& Tilley, N. (1997). Realistic evaluation. Sage.

Radnor, J. M., Moeskops, S., Morris, S. J., Mathews, T. A., Kumar, N. T. A., Pullen, B. J., Meyers, R. W., Pedley, J. S., Gould, Z. I., Oliver, J. L., \& Lloyd, R. S. (2020). Developing Athletic Motor Skill Competencies in Youth. Strength \& Conditioning Journal, 42(6), 54-70. https://doi.org/10.1519/SSC.0000000000000602

Räisänen, A. M., Owoeye, O. B. A., Befus, K., van den Berg, C., Pasanen, K., \& Emery, C. A. (2021). Warm-Ups and Coaches' Perceptions: Searching for Clues to Improve Injury Prevention in Youth Basketball. Frontiers in Sports and Active Living, 3. https://doi.org/10.3389/fspor.2021.619291

Read, P. J., Oliver, J. L., De Ste Croix, M. B. A., Myer, G. D., \& Lloyd, R. S. (2016). The scientific foundations and associated injury risks of early soccer specialisation. Journal of Sports Sciences, 34(24), 2295-2302. https://doi.org/10.1080/02640414.2016.1173221

Rein, R., Davids, K., \& Button, C. (2010a). Adaptive and phase transition behavior in performance of discrete multi-articular actions by degenerate neurobiological systems. Experimental Brain Research, 201(2), 307-322. https://doi.org/10.1007/s00221-009-2040-x

Rein, R., Davids, K., \& Button, C. (2010b). Adaptive and phase transition behavior in performance of discrete multi-articular actions by degenerate neurobiological systems. Experimental Brain Research, 201(2), 307-322. https://doi.org/10.1007/s00221-009-2040-x

Renshaw, I., \& Chow, J.-Y. (2019). A constraint-led approach to sport and physical education pedagogy. Physical Education and Sport Pedagogy, 24(2), 103-116. https://doi.org/10.1080/17408989.2018.1552676

Ribeiro, J., Davids, K., Silva, P., Coutinho, P., Barreira, D., Garganta, J., \& Ribeiro, J. (2021). Talent Development in Sport Requires Athlete Enrichment: Contemporary Insights from a Nonlinear Pedagogy and the Athletic Skills Model. Sports Medicine, 51. https://doi.org/10.1007/s40279-021-01437-6

Richards, K. A. R., \& Hemphill, M. A. (2018). A Practical Guide to Collaborative Qualitative Data Analysis. Journal of Teaching in Physical Education, 37(2), 225-231. https://doi.org/10.1123/jtpe.2017-0084

Richards, K. A. R., \& Templin, T. J. (2012). Toward a Multidimensional Perspective on TeacherCoach Role Conflict. Quest, 64(3), 164-176. https://doi.org/10.1080/00336297.2012.693751

Richards, K. A. R., Templin, T. J., \& Gaudreault, K. L. (2013). Understanding the Realities of School Life: Recommendations for the Preparation of Physical Education Teachers. Quest, 65(4), 442-457. https://doi.org/10.1080/00336297.2013.804850

Roberts, A., Greenwood, D., Stanley, M., Humberstone, C., Iredale, F., \& Raynor, A. (2019). Coach knowledge in talent identification: A systematic review and meta-synthesis. Journal of Science and Medicine in Sport, 22. https://doi.org/10.1016/j.jsams.2019.05.008

Rongen, F., McKenna, J., Cobley, S., \& Till, K. (2018). Are youth sport talent identification and development systems necessary and healthy? Sports Medicine - Open, 4(1), 18. https://doi.org/10.1186/s40798-018-0135-2

Santos, S. D. L., Memmert, D., Sampaio, J., \& Leite, N. (2016). The Spawns of Creative Behavior in Team Sports: A Creativity Developmental Framework. Frontiers in Psychology, 7. https://doi.org/10.3389/fpsyg.2016.01282 
605

606

607

608

609

610

611

612

613

614

615

616

617

618

619

620

621

622

623

624

625

626

627

628

629

630

631

632

633

634

635

636

637

638

639

640

641

642

643

644

645

646

647

648

649

650

651

652
Santos, S., Mateus, N., Sampaio, J., \& Leite, N. (2017). Do previous sports experiences influence the effect of an enrichment programme in basketball skills? Journal of Sports Sciences, 35(17), 1759-1767. https://doi.org/10.1080/02640414.2016.1236206

Saunders, N., Otago, L., Romiti, M., Donaldson, A., White, P., \& Finch, C. (2010). Coaches' perspectives on implementing an evidence-informed injury prevention programme in junior community netball. British Journal of Sports Medicine, 44(15), 1128-1132. https://doi.org/10.1136/bjsm.2009.069039

Schelling, X., \& Torres-Ronda, L. (2016). An Integrative Approach to Strength and Neuromuscular Power Training for Basketball. Strength \& Conditioning Journal, 38(3), 72-80. https://doi.org/10.1519/SSC.0000000000000219

Seifert, L., Wattebled, L., Herault, R., Poizat, G., Adé, D., Gal-Petitfaux, N., \& Davids, K. (2014). Neurobiological Degeneracy and Affordance Perception Support Functional Intra-Individual Variability of Inter-Limb Coordination during Ice Climbing. PLoS ONE, 9(2), e89865. https://doi.org/10.1371/journal.pone.0089865

Smith, B. (2018). Generalizability in qualitative research: Misunderstandings, opportunities and recommendations for the sport and exercise sciences. Qualitative Research in Sport, Exercise and Health, 10(1), 137-149. https://doi.org/10.1080/2159676X.2017.1393221

Smith, B., Bundon, A., \& Best, M. (2016). Disability sport and activist identities: A qualitative study of narratives of activism among elite athletes' with impairment. Psychology of Sport and Exercise, 26, 139-148. https://doi.org/10.1016/j.psychsport.2016.07.003

Smith, B., Tomasone, J. R., Latimer-Cheung, A. E., \& Martin Ginis, K. A. (2015). Narrative as a knowledge translation tool for facilitating impact: Translating physical activity knowledge to disabled people and health professionals. Health Psychology, 34(4), 303-313. https://doi.org/10.1037/hea0000113

Smith, W. (2016). Fundamental movement skills and fundamental games skills are complementary pairs and should be taught in complementary ways at all stages of skill development. Sport, Education and Society, 21(3), 431-442. https://doi.org/10.1080/13573322.2014.927757

Soares, A. L. A., Kós, L. D., Paes, R. R., Nascimento, J. V., Collins, D., Gonçalves, C. E., \& Carvalho, H. M. (2020). Determinants of drop-out in youth basketball: An interdisciplinary approach. Research in Sports Medicine, 28(1), 84-98. https://doi.org/10.1080/15438627.2019.1586708

Spaaij, R., Magee, J., Farquharson, K., Gorman, S., Jeanes, R., Lusher, D., \& Storr, R. (2018). Diversity work in community sport organizations: Commitment, resistance and institutional change. International Review for the Sociology of Sport, 53(3), 278-295. https://doi.org/10.1177/1012690216654296

Sparkes, A. C. (Ed.). (2014). Qualitative research methods in sport, exercise and health: From process to product. Routledge.

Sugimoto, D., Jackson, S. S., Howell, D. R., Meehan, W. P., \& Stracciolini, A. (2019). Association between training volume and lower extremity overuse injuries in young female athletes: Implications for early sports specialization. The Physician and Sportsmedicine, 47(2), 199204. https://doi.org/10.1080/00913847.2018.1546107

Tinning, R. (2011). Pedagogy and human movement: Theory, practice, research (1. issued in paperback). Routledge.

Tracy, S. J. (2010). Qualitative Quality: Eight “Big-Tent” Criteria for Excellent Qualitative Research. Qualitative Inquiry, 16(10), 837-851. https://doi.org/10.1177/1077800410383121

Trainor, L. R., \& Bundon, A. (2020). Developing the craft: Reflexive accounts of doing reflexive thematic analysis. Qualitative Research in Sport, Exercise and Health, 1-22. https://doi.org/10.1080/2159676X.2020.1840423 
653

654

655

656

657

658

659

660

661

662

663

664

665

666

667

668

669

670

671
Woods, C. T., McKeown, I., Keogh, J., \& Robertson, S. (2017). The association between fundamental athletic movements and physical fitness in elite junior Australian footballers. Journal of Sports Sciences, 1-6. https://doi.org/10.1080/02640414.2017.1313996

Wormhoudt, R., Savelsbergh, G. J. P., Teunissen, J. W., \& Davids, K. (2018). The athletic skills model: Optimizing talent development through movement education. Routledge.

Wright, P. M., Gray, S., \& Richards, K. A. R. (2021). Understanding the interpretation and implementation of social and emotional learning in physical education. The Curriculum Journal, 32(1), 67-86. https://doi.org/10.1002/curj.85

Young, L., O'Connor, J., Alfrey, L., \& Penney, D. (2020). Assessing physical literacy in health and physical education. Curriculum Studies in Health and Physical Education, 1-24. https://doi.org/10.1080/25742981.2020.1810582

Youth Basketball Guidelines. (n.d.). Youth Basketball Guidelines. Retrieved 27 August 2020, from https://youthguidelines.nba.com/

Zoellner, A., Whatman, C., Read, P., \& Sheerin, K. (2021). The association between sport specialisation and movement competency in youth: A systematic review. International Journal of Sports Science \& Coaching, 174795412199845.

https://doi.org/10.1177/1747954121998456 
673 Table 1 - Coaching survey questions (mapped to Realist Evaluation concepts of Mechanisms, 674 Contexts and Outcomes)

\begin{tabular}{|c|c|c|c|}
\hline Question & & $\begin{array}{l}\text { Additional } \\
\text { information }\end{array}$ & Answer format \\
\hline 1. & $\begin{array}{l}\text { Please state the country where you are } \\
\text { located }\end{array}$ & - & Open-ended \\
\hline 2. & $\begin{array}{l}\text { Please state the age group of the } \\
\text { players that you predominantly } \\
\text { currently coach }\end{array}$ & $\begin{array}{l}\text { Example: under } \\
13 \mathrm{~s}\end{array}$ & Open-ended \\
\hline 3. & Please state the sex of the players & - & $\begin{array}{l}\text { Check boxes: } \\
\text { male; female }\end{array}$ \\
\hline 4. & $\begin{array}{l}\text { Please provide an approximation of } \\
\text { coaching sessions per week and total } \\
\text { time delivering supervised coaching } \\
\text { sessions to the players }\end{array}$ & $\begin{array}{l}\text { Number of } \\
\text { sessions per week } \\
\text { followed by } \\
\text { number of } \\
\text { coaching hours } \\
\text { per week }\end{array}$ & Open-ended \\
\hline 5. & $\begin{array}{l}\text { Briefly describe your understanding of } \\
\text { what fundamental movement skills are } \\
\text { (mechanism) }\end{array}$ & - & Open-ended \\
\hline 6. & $\begin{array}{l}\text { Do you include non-basketball specific } \\
\text { exercises / activities in the warm-up } \\
\text { ahead of main practice content? } \\
\text { (mechanism) }\end{array}$ & $\begin{array}{l}\text { Activities that do } \\
\text { not involve } \\
\text { basketball specific } \\
\text { actions }\end{array}$ & $\begin{array}{l}\text { Multiple choice: } \\
\text { yes; no; or } \\
\text { sometimes }\end{array}$ \\
\hline 7. & $\begin{array}{l}\text { Would you feel confident to deliver } \\
\text { non-basketball specific warm-up } \\
\text { exercises that target general } \\
\text { athleticism? (context) }\end{array}$ & - & $\begin{array}{l}\text { Check boxes, yes } \\
\text { or no }\end{array}$ \\
\hline 8. & $\begin{array}{l}\text { Do you believe there would be value in } \\
\text { including general athletic exercises } \\
\text { into your coaching session? (outcome) }\end{array}$ & - & $\begin{array}{l}\text { Multiple choice: } \\
\text { yes; no; maybe }\end{array}$ \\
\hline 9. & $\begin{array}{l}\text { If you answered no to the previous } \\
\text { question, please provide a brief } \\
\text { explanation why you provided this } \\
\text { answer (context) }\end{array}$ & - & Open-ended \\
\hline 10. & $\begin{array}{l}\text { Please indicate if you include any of } \\
\text { the following athletic movement } \\
\text { patterns within any part of your } \\
\text { basketball coaching session (outcome) }\end{array}$ & $\begin{array}{l}\text { Please tick boxes } \\
\text { for athletic } \\
\text { movement } \\
\text { patterns included } \\
\text { in your basketball } \\
\text { session }\end{array}$ & $\begin{array}{l}\text { Checkboxes: } \\
\text { squat; lunge; hip- } \\
\text { hinge; landing } \\
\text { technique; } \\
\text { pushing; pulling; } \\
\text { bridging }\end{array}$ \\
\hline
\end{tabular}




\begin{tabular}{|c|c|c|c|}
\hline 11. & $\begin{array}{l}\text { If you answered yes to any of the } \\
\text { exercises listed in the previous } \\
\text { question, please indicate an } \\
\text { approximate frequency per week that } \\
\text { the players are requested to perform } \\
\text { them (outcome) }\end{array}$ & $\begin{array}{l}\text { This can include } \\
\text { as part of a game } \\
\text { day warm up as } \\
\text { well as within } \\
\text { practice sessions }\end{array}$ & $\begin{array}{l}\text { Multiple choice: } \\
\text { once per week; } \\
\text { twice per week; } \\
\text { three times per } \\
\text { week; four or } \\
\text { more times per } \\
\text { week }\end{array}$ \\
\hline 12 & $\begin{array}{l}\text { How proficient would you rate the } \\
\text { players to be at performing these } \\
\text { athletic movement patterns with } \\
\text { respect to control and stability? } \\
\text { (context) }\end{array}$ & - & $\begin{array}{l}\text { Multiple choice: } \\
\text { very; fairly; not }\end{array}$ \\
\hline
\end{tabular}

675 